
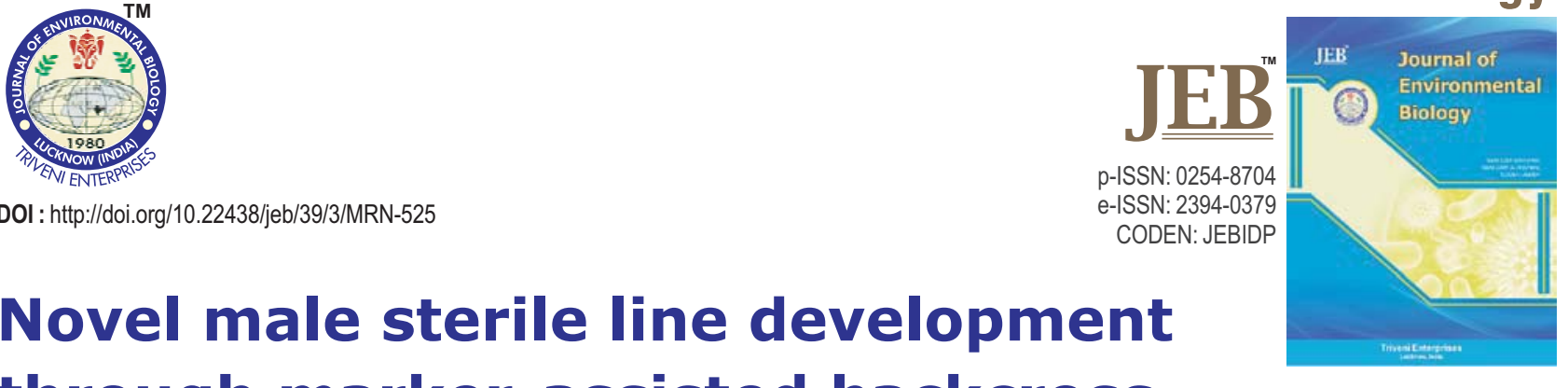

\title{
Novel male sterile line development through marker-assisted backcross breeding suitable for aerobic planting in rice
}

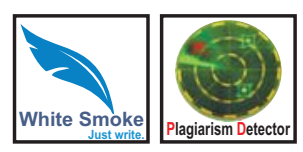

\section{Authors Info}

\section{P. Raghavendra* and S. Hittalmani}

Marker Assisted Selection Laboratory, Department of Genetics and Plant Breeding, University of Agricultural Sciences, GKVK, Bangalore-560 065, India

*Corresponding Author Email : raghavendra9078@gmail.com

Key words

Aerobic condition

Male sterile line

Marker-assisted backcross

Rice hybrid

SSR markers

Publication Info

Paper received : 30.11 .2016

Revised received : 16.02 .2017

Re-revised received: 27.09.2017

Accepted : 29.09 .2017

\section{Abstract}

Aim : Availability of suitable hybrids for drought or cultivation under aerobic situation is scarce in rice. Therefore, there is a dire need for developing of potential male sterile line for the production of promising hybrids. In this way, present study conducted was development of male sterile line suitable for aerobic rice hybrids in limited generations with the use of marker assisted backcrossing.

Methodology : The present study was conducted using strategy of marker assisted background selection for the development of new malesterile line in rice. A male sterile line KCMS31A was used as a donor parent for male sterility and a promising genotype MAS99 (early maturing and suitable for aerobic condition) as a recurrent parent. Backcrossing was carried out from 2013 to 2014. Phenotypic foreground selection was carried out in each generation by pollen fertility test. Based on parental polymorphism survey, 96 polymorphic SSR markers were identified and utilised for the marker assisted background selection in $\mathrm{BC}_{3} \mathrm{~F}_{1}$ generation. Further, $\mathrm{BC}_{4} \mathrm{~F}_{1}$ plants were evaluated for morphological characters.

Results : Analysis of data showed that all the plants were totally male sterile and the plants coded as $\mathrm{BC}_{3} \mathrm{~F}_{1}-5-7 \quad(96.88 \%), \quad \mathrm{BC}_{3} \mathrm{~F}_{1}-5-10$ (96.88\%), BC $\mathrm{BC}_{3}-5-15(96.88 \%)$ and $\mathrm{BC}_{3} \mathrm{~F}_{1}-5-17$ $(95.83 \%)$ were found to be recovered maximum recurrent parent genome and they were advanced to $\mathrm{BC}_{4} \mathrm{~F}_{1}$. Evaluation of new $\mathrm{BC}_{4} \mathrm{~F}_{1}$ male sterile line pertaining to morphological traits revealed that the trait means were on par with the original fertile counterpart MAS $99 \mathrm{~B}$ line.

Interpretation : The results confirmed the supremacy of marker assisted selection in backcross breeding aimed at the recovery of recurrent parent genome as quickly as possible and this is the first effort made by authors to develop male sterile line fit to utilise in hybrid rice programme under aerobic condition.

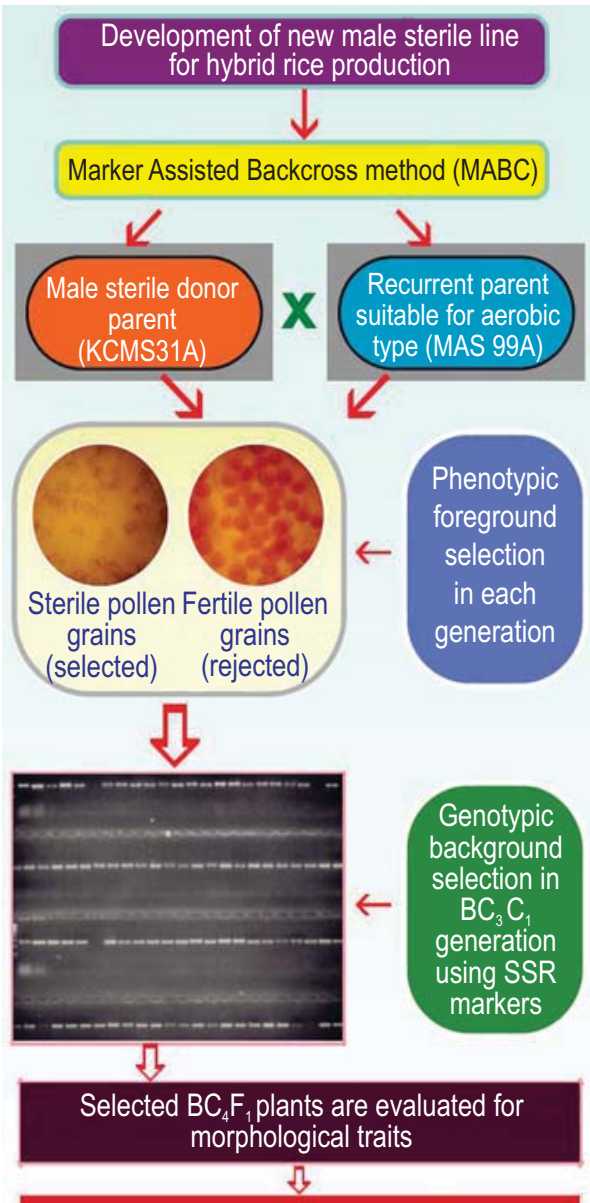

New male sterile line (MAS99A) suitable for aerobic condition in rice 


\section{Introduction}

Cytoplasmic genetic male sterility results due to interaction of nuclear genes and mitochondrial genes (Maureen and Stephane, 2004). The role of cytoplasm in causing male sterility in rice was first reported in 1954 (Sampath and Mohantu, 1954). Later, Katsuo and Mizushima (1958) also observed a similar phenomenon in the progeny of first backcross of Oryza sativa F. spontanea / Oryzasativa c. eujisakos. Since, rice is a self-pollinated crop, crossing work involves tedious hand emasculation and pollination, hence, the availability of suitable male sterile lines would render hybridization process easier (Hittalmani and Shivashanker, 1987). Among different male sterile sources, wild abortive male sterility is extensively used male sterile source in hybrid rice seed industry, i.e, approximately $90 \%$ of hybrids (Rajand Virmani, 1987; Yao et al., 1997; Zhang et al., 2002). But till now male sterility source has not been diversified for aerobic condition. Aerobic rice is considered as promising rice cultivation system as water scarcity is increasing in the world (Kumar et al., 2015). Compared with lowland rice, water requirement in aerobic rice is reduced by more than $50 \%$, and water productivity increases by $60 \%$ (Nareshbabu et al., 2010; Gandhi et al., 2011). Hittalmani and Shivashankar (1987) demonstrated that rice can be cultivated in dry sowing (aerobic) while attempting crosses using local rice of Karnataka. So there is a dire need to develop male sterile line suitable for aerobic condition. It has been reported that backcross breeding is a wellknown technique of transferring a target trait from donor line in to the genetic background of a recipient line. However, for recovery of entire recurrent parent genome, it needs repeated backcrosses (up to 7 times). This process is time consuming and the rate of recovery of the recurrent parent genome based on phenotypic selection is not efficient (Young and Tanksley, 1989; Neeraja et al., 2006; Liu et al., 2006; Semgan et al., 2006). Hence, an alternative for this is to go for marker assisted backcrossing to retrieve the recurrent parent genome in limited generations. The efficiency of selection significantly upturned by the usage of molecular markers in backcross programme. This strategy is rapid and very effective compared to phenotypic selection (Hospital, 2009). Markers can be used in combination with or to replace phenotypic screening for the target background which is referred as 'background selection' (Tanksley et al., 1989; Hospital and Charcosset, 1997; Bouchez et al., 2002). A minimum of two backcrosses are required in case of very short distances between molecular marker and the gene of interest (Hospital, 2001). Whereas, Bai et al. (2006) showed that only three backcrosses were enough to recover $98 \%$ of recipient parent genome. The success of this approach depends on the strategy of selection, marker density, size of population, recurrent parent genome and design of experiment (Frisch and Melchinger, 2005). More recently in Vietnam, QTL SUB1 has been introgressed using MABB approach into an elite rice variety (Luu et al., 2012). Limited availability and low variation of male sterile lines leads to genetic vulnerability. Therefore, breeders can transfer male sterility to the existing putative $B$ lines through repeated backcrosses to diversify male sterile lines (Manivannan et al., 2011).
Researchers have shown that MAS99 B line has Iff genotype, and hence is a putative maintainer line for wild abortive type male sterility. Thus, it can be potentially converted to a male sterile line using marker-assisted backcross breeding (MABB) method for accelerating the recovery rate of recurrent parent genome in fewer generations. Therefore, the present study aimed to develop male sterile line in MAS99 background from KCMS31A as donor male sterility source in limited backcrosses, which could be further exploited for hybrid rice seed production under aerobic condition. This is the first effort to develop a malesterile line suitable for aerobic condition using MABB.

\section{Materials and Methods}

Plant materials : In the present study an elite maintainer line MAS99 B line was used as male recipient parent, which was of short duration and suitable for aerobic condition. KCMS31 male sterile line was used as female donor parent. In kharif 2012, hybridization was affected between these two and $43 \mathrm{~F}_{1}$ plants were developed. First backcross was affected in summer 2013 and established $58 \mathrm{BC}_{1} \mathrm{~F}_{1}$ plants, selected plants which were synchronised in flowering with MAS99 were backcrossed subsequently to establish 32 and 45 plants in $\mathrm{BC}_{2} \mathrm{~F}_{1}$ and $\mathrm{BC}_{3} \mathrm{~F}_{1}$ respectively. Phenotypic foreground selection in each generations using pollen fertility test was carried out. In $\mathrm{BC}_{3} \mathrm{~F}_{1}$ marker assisted background selection was carried out to obtain $\mathrm{BC}_{4} \mathrm{~F}_{1}$. The resultant $\mathrm{BC}_{4} \mathrm{~F}_{1}$ male sterile plants were evaluated along with parents for morphological traits according to standard evaluation system for rice (1996) under aerobic condition.

Aerobic rice cultivation : Under aerobic cultivation method, seeds were sown directly in unpuddled land unlike in wetland rice where rice was transplanted after growing in nursery. Standard spacing of $30 \mathrm{~cm}$ between rows and $25 \mathrm{~cm}$ between plants were maintained. The soil moisture was maintained at field capacity during entire crop growth period by irrigating at 5-6 days interval. The aeration of soil was maintained in contrast to anaerobic condition in case of puddled transplanted rice. Further, during reproductive stage irrigation was increased once in 3 days.

Sampling and DNA extraction : Young vigorously grown fresh leaf samples from $\mathrm{KCMS} 31 \mathrm{~A} \times \mathrm{MAS} 99$ cross derived $\mathrm{BC}_{3} \mathrm{~F}_{1}$ progenies were collected from 25-day-old seedlings to extract genomic DNA of 45 individuals. The modified cetyltrimethyl ammonium bromide method was adapted to obtain DNA of individuals (Cao and Oard, 1997).

Marker assisted background selection : Parental polymorphism marker survey was initially conducted to identify polymorphic markers between the parents using 412 SSR markers that covered all 12 rice chromosomes. 96 polymorphic SSR markers on an average of 8 markers per chromosome were used for amplification of $\mathrm{BC}_{3} \mathrm{~F}_{1}$ progenies along with parents.Scoring of $\mathrm{BC}_{3} \mathrm{~F}_{1}$ genotypes was done based on recurrent and donor parent banding pattern, if the bands were like donor parent (KCMS31A) 
then individuals were scored as ' $A$ '. Similarly, if the bands were like recurrent parent (MAS99) then it was scored as 'B'. Since diploids have 2 alleles, we considered number of allele as twice the number of markers used, therefore for the present study total number of alleles became 192. Similarly, twice the number of $A$ and $B$ alleles were considered in calculation of recurrent parent genome recovery symbolically given below.

Recurrent parent genome recovery (\%)

Number of recurrent parent alleles $(B)+1 / 2$ of heterozygote alleles $(H)$

Total number of marker alleles checked (A\&B)

Further, for pictorial visualisation of parental segments in $\mathrm{BC}_{3} \mathrm{~F}_{1}$ progenies, resultant genotypic data was subjected to graphical genotypic analysis using GGT v.2.0 software package (Berloo, 2008).

Evaluation of new male sterile line : The performance of new male sterile line was evaluated along with parents KCMS31A and MAS 99 under field condition in two replications for morphological traits at $\mathrm{BC}_{4} \mathrm{~F}_{1}$ generation. Observations were documented on sterility of pollen(\%) using $2 \%$ acetocarmine dye, days to $50 \%$ flowering, plant height at the time of maturity $(\mathrm{cm})$, days to maturity, length of panicle, number of spikelet's/panicle, spikelet sterility (\%). An average of ten plants of new male sterile lines and parents observations were considered for comparison using 't'test with the help of SPSS 16.0 software.

\section{Results and Discussion}

The inefficiency of selection based on phenotype has been noticed in previous studies emphasizing the limitations associated with traditional backcross breeding for complete recovery of recurrent parent genome (Yi et al., 2009). With the advent of molecular markers gene mapping was achieved, which helped to identify molecular makers linked to gene of interest. Those markers could be used in maker assisted selection. Among different approaches, marker assisted backcross breeding $(\mathrm{MABB})$ is one which could be exploited for transfer of specific genomic regions in to recipient parent background with high efficiency (Kumar and Hittalmani, 2000; Jena and Mackill, 2008).

The observations of pollen fertility test revealed complete male sterility of $F_{1}$ plants derived from KCMS31 x MAS 99 cross, indicated that MAS99 behaved as maintainer genotype. This paved the way for us to convert maintainer MAS 99 into new male sterile line (Fig.1). Subsequently, all the back cross derived progenies were also found to be completely male sterile $(100 \%)$ even after three consecutive backcross with recurrent parent MAS99. In each generation, stringent phenotypic selection followed with a foremost attention on sterility and flowering synchronization with MAS99 genotype for the selection of plants. The observed stable male sterility even after several backcrosses confirmed that interaction of

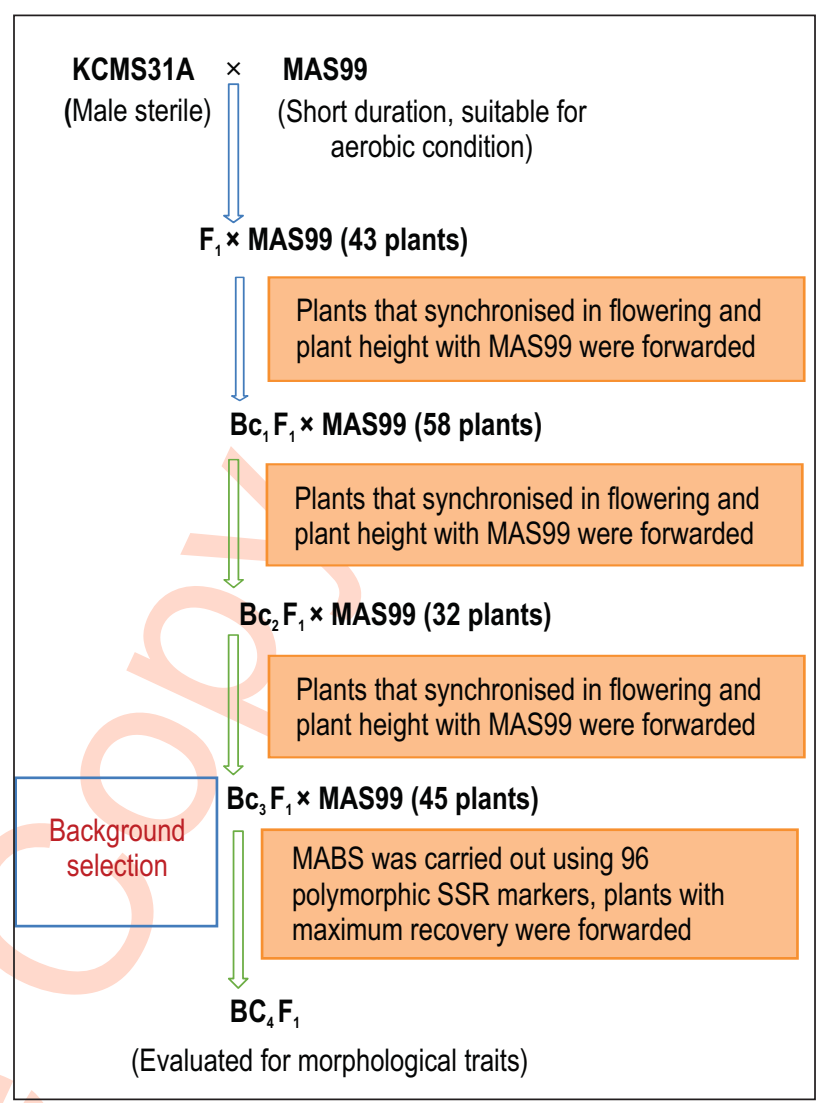

Fig.1 : Marker assisted backcross breeding strategy followed to develop new male sterile line

Table 1 : Details of polymorphism survey of SSR markers on parents of $\mathrm{BC}_{3} \mathrm{~F}_{1}$ progenies derived from $\mathrm{KCMS} 31 \mathrm{~A} \times \mathrm{MAS} 99$ cross in rice

\begin{tabular}{llll}
\hline $\begin{array}{l}\text { Chromosome } \\
\text { number }\end{array}$ & $\begin{array}{l}\text { Total SSR } \\
\text { markers } \\
\text { screened }\end{array}$ & $\begin{array}{l}\text { No. of } \\
\text { polymorphic } \\
\text { SSR markers }\end{array}$ & $\begin{array}{l}\text { Percent } \\
\text { polymorphism }\end{array}$ \\
\hline 1 & 75 & 15 & 20.00 \\
2 & 35 & 8 & 22.86 \\
3 & 38 & 6 & 15.79 \\
4 & 30 & 12 & 40.00 \\
5 & 43 & 10 & 23.26 \\
6 & 35 & 7 & 20.00 \\
7 & 33 & 8 & 24.24 \\
8 & 42 & 4 & 9.52 \\
9 & 46 & 8 & 17.39 \\
10 & 28 & 4 & 14.29 \\
11 & 36 & 3 & 8.33 \\
12 & 42 & 11 & 26.19 \\
Total & 483 & 96 & Average $=20.16$ \\
\hline
\end{tabular}

cytoplasm with new nucleus in such a manner would caused complete male sterility i.e., without any adverse background effect, incomplete penetrance or variable expressivity etc. Because, in presence of these conditions, there will be a existence 


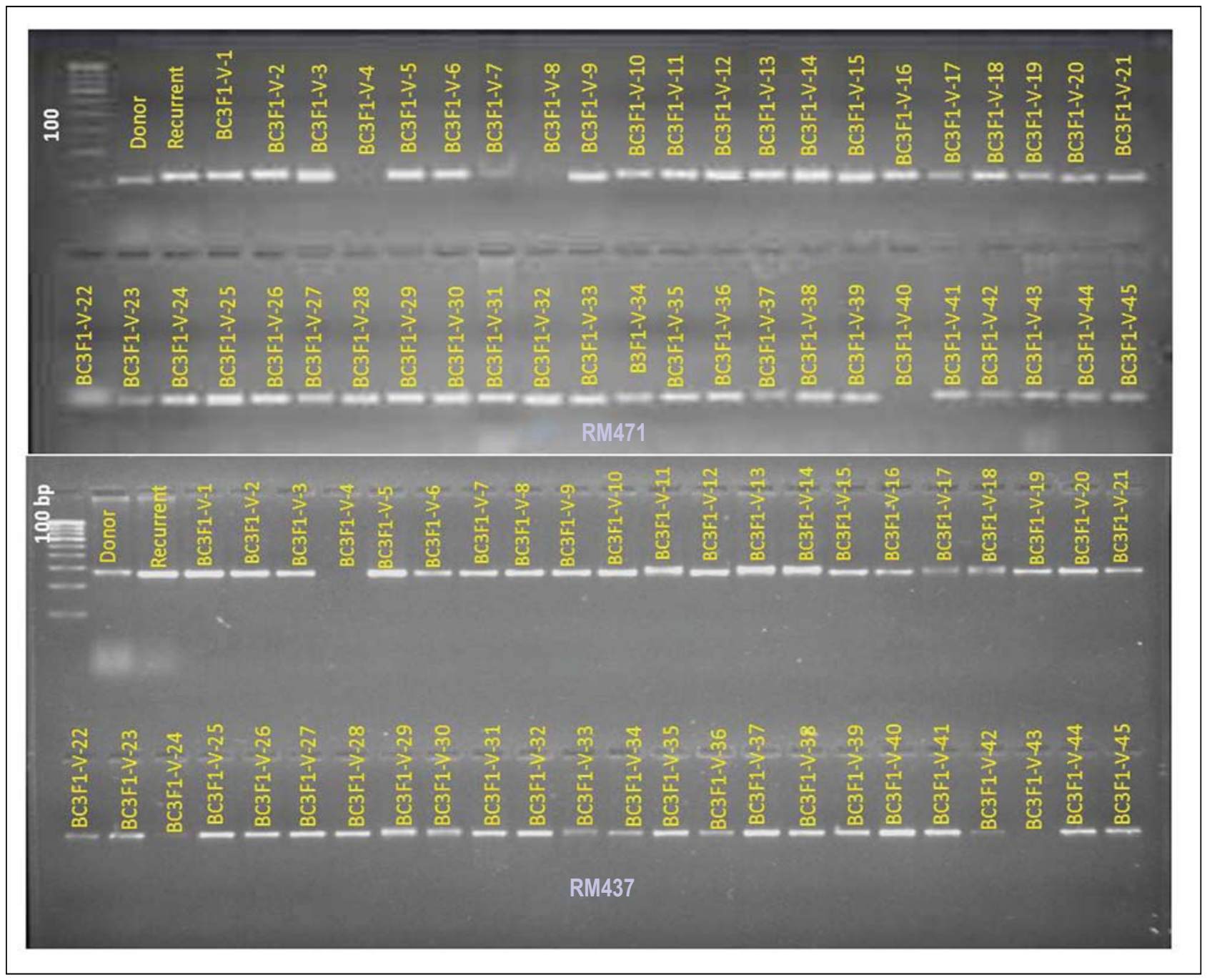

Fig. 2 : A sample of electrophoresis banding pattern of RM471 and RM437 SSR markers showing amplification of $45 \mathrm{BC}_{3} \mathrm{~F}_{1}$ s of cross KCMS31A (Donor) $\times$ MAS99 (Recurrent)

of partial fertile /sterile plants to some extent, similarly presence of complete male sterility was reported by Ahmadikha et al.(2015).

The parental DNA polymorphism is a pre requisite for any marker assisted selection. Hence, in this study a total of 412 SSR markers covering all 12 rice chromosomes were used to identify DNA polymorphic markers between two parents. The results showed that among 412 SSR markers, 96 were polymorphic (Table 1) indicating the presence of genetic variability at different locus on chromosome between parental materials. These polymorphic markers help us to determine the parent of origin of DNA segments. On an average, the percent polymorphic markers on parental survey was approximately $20.16 \%$ with highest polymorphism in chromosome $4(40 \%)$ and lowest polymorphism in chromosome 11 (8\%). Further, these 96 polymorphic SSR markers were used for background selection to check the proportion of recurrent parent genome recovery. Similarly, Hien et al. (2012) observed average polymorphism of $24 \%$ for salt tolerance between the parents and Ahmadikhah et al. (2015) reported 34\% of polymorphism between donor and recurrent parent.

The marker assisted background selection has been advised for rapid recovery of recurrent parent genome in early generations of backcross population (Chen et al., 2001; Joseph et al., 2004).In the present study, an average of eight SSR markers per chromosome in background selection in the present study (Fig.2; Fig.3). In $\mathrm{BC}_{3} \mathrm{~F}_{1}$ progenies derived from KCMS31A $\times$ MAS99 cross the observed proportion of recurrent parent genome using SSR marker data ranged from 87.50 to $96.88 \%$. Out of 45 plants analysed, 16 were found to be recovered more than or equal to expected recovery percentage of recurrent parent genome (MAS99). The highest recovery 


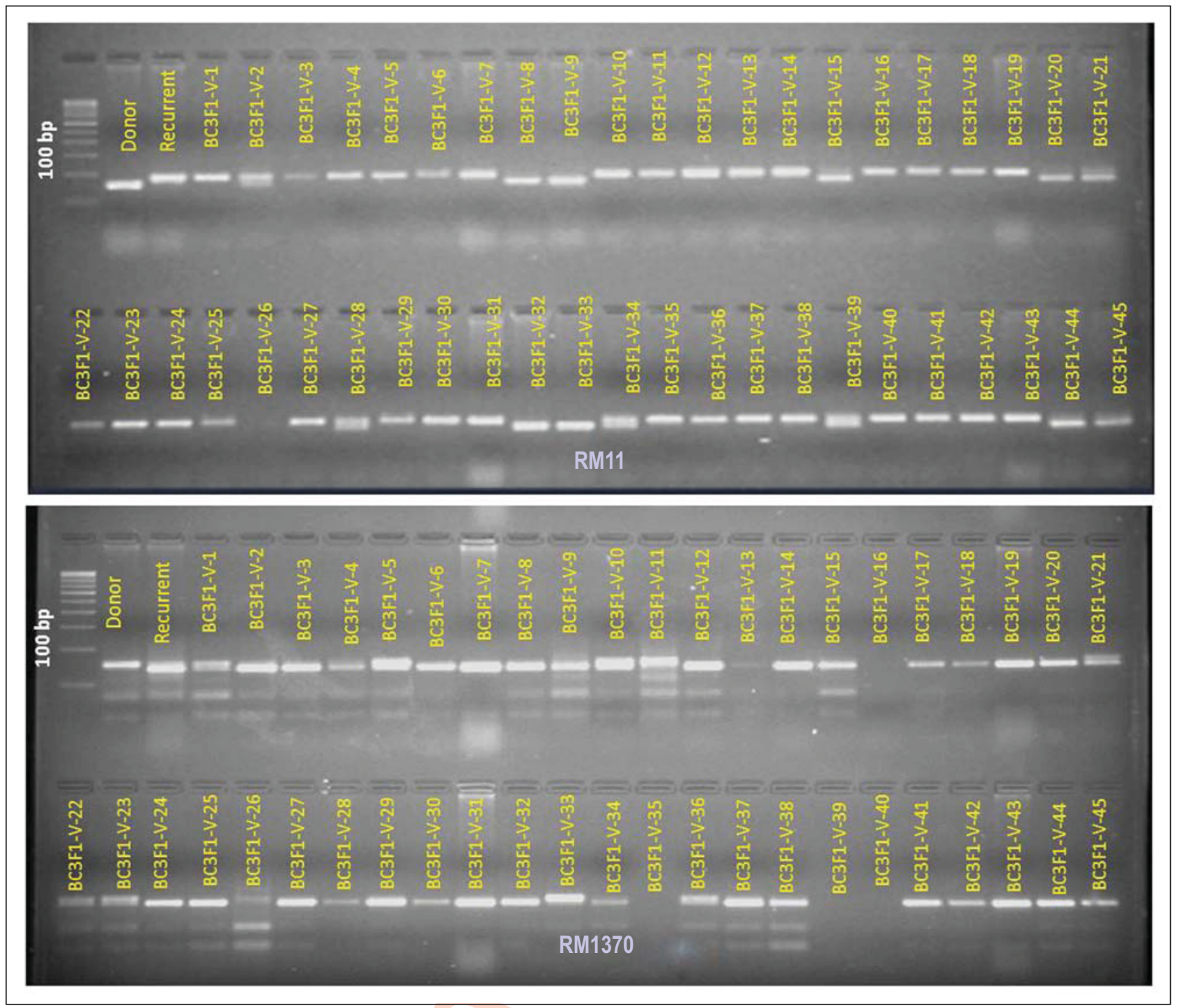

Fig. 3 : A sample of electrophoresis banding pattern of RM11 and RM1370 SSR markers showing amplification of $45 \mathrm{BC}_{3} \mathrm{~F}_{1} \mathrm{~s}_{\mathrm{S}}$ of cross $\mathrm{KCMS} 31 \mathrm{~A}$ (Donor) $\times$ MAS99 (Recurrent)

was by plants $\mathrm{BC}_{3} \mathrm{~F}_{1}-10, \mathrm{BC}_{3} \mathrm{~F}_{1}-15$ and $\mathrm{BC}_{3} \mathrm{~F}_{1}-7$ (96.88\%), whereas the lowest recovery of $87.50 \%$ was recorded by the $40^{\text {th }}$ individual (Table 2).

The plants $\mathrm{BC}_{3} \mathrm{~F}_{1}-5-7(96.88 \%), \mathrm{BC}_{3} \mathrm{~F}_{1}-5-10(96.88 \%)$, $\mathrm{BC}_{3} \mathrm{~F}_{1}-5-15(96.88 \%), \mathrm{BC}_{3} \mathrm{~F}_{1}-5-17(95.83 \%), \mathrm{BC}_{3} \mathrm{~F}_{1}-5-24$ (95.83\%) and $\mathrm{BC}_{3} \mathrm{~F}_{1}-5-42$ (95.83\%) were superior in genome recovery recurrent parent (Table 2), hence they were forwarded to $\mathrm{BC}_{4} \mathrm{~F}_{1}$. Whereas, $64.4 \%$ of the plants i.e., 29 plants recovered less than average recovery $(93.75 \%)$. Thus, by using markers these plants were eliminated otherwise by conventional way we would have selected plants which recovered lesser 'MAS99' genome. Further, we may have to go for more number of backcrosses. This difference in recovery percentage was due to difference in contribution of proportion of genomic regions of parents which was consequence of variation in occurrence of recombination and presence of linkage of genes present on the chromosome. Similarly, the MABB approach was utilized for development of variety resistance to rice stripe virus resistance using 47 markers, which accounts nearly four markers per chromosome (Pan et al., 2009). In the same way, forty three SSR markers ( $<4$ markers per chromosome) were used for background selection to develop new male sterile line in rice fit to wet land condition (Ahmadikhah et al., 2015). Whereas Yi et al. (2009) used nearly three markers per chromosome to develop rice variety with improved cooking quality. Marker density used for background selection was more than the previous studies. Further, graphical genotyping 


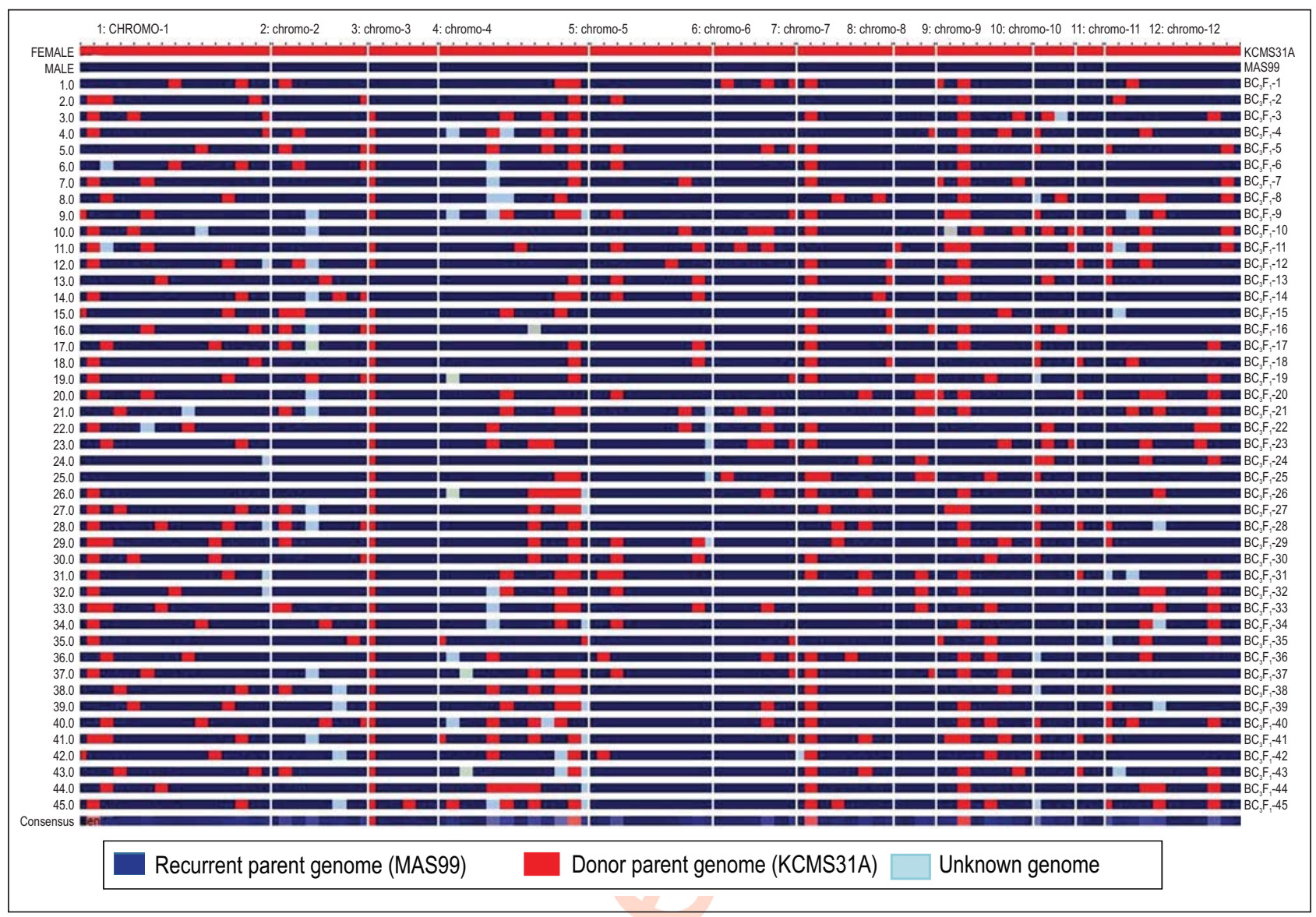

Fig. 4 : Genomic regions of recurrent parent and donor parent visualized by Graphical genotyping of 12 linkage groups of $45 \mathrm{BC}_{3} \mathrm{~F}_{1} s$ derived from $\mathrm{KCMS} 31 \mathrm{~A} \times \mathrm{MAS} 99$ crossin rice

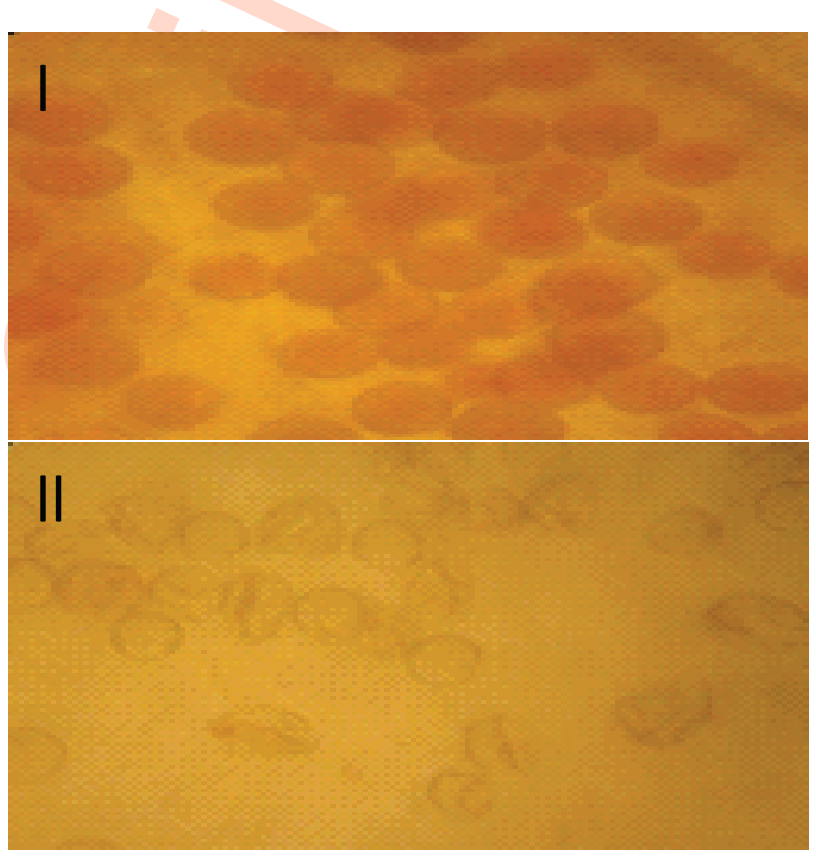

Fig. 5 : Comparison of fertile pollens of MAS 99B plants (I) and sterile pollens of MAS 99A plants (II) visualized by light microscope (40x) after 2\% acetocarmine staining 
Table 2 : Proportion of recurrent parental genome observed in $\mathrm{BC}_{3} \mathrm{~F}_{1}$ progenies of cross $\mathrm{KCMS} 31 \mathrm{~A} \times \mathrm{MAS} 99$ using rice SSR markers

\begin{tabular}{|c|c|c|c|c|c|c|}
\hline Plant no. & $\begin{array}{l}\text { Total } \\
\text { no. of } \\
\text { alleles }\end{array}$ & $\begin{array}{l}\text { Recurrent } \\
\text { parent } \\
\text { allele }\end{array}$ & $\begin{array}{l}\text { Donor } \\
\text { parent } \\
\text { allele }\end{array}$ & $\begin{array}{l}\text { Percent } \\
\text { recurrent genome } \\
\text { recovered (1) }\end{array}$ & $\begin{array}{l}\text { Expected } \\
\text { recurrent parent } \\
\text { genome recovery* }(2)\end{array}$ & $\begin{array}{l}\text { Difference } \\
(2-1)\end{array}$ \\
\hline BC3F1-5-1 & 192 & 178 & 14 & 92.71 & 93.75 & -1.04 \\
\hline BC3F1-5-2 & 192 & 178 & 14 & 92.71 & 93.75 & -1.04 \\
\hline $\mathrm{BC} 3 \mathrm{~F} 1-5-3$ & 192 & 174 & 18 & 90.63 & 93.75 & -3.12 \\
\hline BC3F1-5-4 & 192 & 180 & 12 & 93.75 & 93.75 & 0.00 \\
\hline BC3F1-5-5 & 192 & 178 & 14 & 92.71 & 93.75 & -1.04 \\
\hline BC3F1-5-6 & 192 & 180 & 12 & 93.75 & 93.75 & 0.00 \\
\hline BC3F1-5-7 & 192 & 186 & 06 & 96.88 & 93.75 & 3.13 \\
\hline BC3F1-5-8 & 192 & 179 & 13 & 93.23 & 93.75 & -0.52 \\
\hline BC3F1-5-9 & 192 & 176 & 16 & 91.67 & 93.75 & -2.08 \\
\hline BC3F1-5-10 & 192 & 186 & 06 & 96.88 & 93.75 & 3.13 \\
\hline BC3F1-5-11 & 192 & 174 & 18 & 90.63 & 93.75 & -3.12 \\
\hline BC3F1-5-12 & 192 & 174 & 18 & 90.63 & 93.75 & -3.12 \\
\hline BC3F1-5-13 & 192 & 178 & 14 & 92.71 & 93.75 & -1.04 \\
\hline BC3F1-5-14 & 192 & 184 & 08 & 95.83 & 93.75 & 2.08 \\
\hline BC3F1-5-15 & 192 & 186 & 06 & 96.88 & 93.75 & 3.13 \\
\hline BC3F1-5-16 & 192 & 178 & 14 & 92.71 & 93.75 & -1.04 \\
\hline BC3F1-5-17 & 192 & 184 & 08 & 95.83 & 93.75 & 2.08 \\
\hline BC3F1-5-18 & 192 & 180 & 12 & 93.75 & 93.75 & 0.00 \\
\hline BC3F1-5-19 & 192 & 178 & 14 & 92.71 & 93.75 & -1.04 \\
\hline BC3F1-5-20 & 192 & 174 & 18 & 90.63 & 93.75 & -3.12 \\
\hline BC3F1-5-21 & 192 & 176 & 16 & 91.67 & 93.75 & -2.08 \\
\hline BC3F1-5-22 & 192 & 182 & 10 & 94.79 & 93.75 & 1.04 \\
\hline BC3F1-5-23 & 192 & 176 & 16 & 91.67 & 93.75 & -2.08 \\
\hline BC3F1-5-24 & 192 & 184 & 08 & 95.83 & 93.75 & 2.08 \\
\hline BC3F1-5-25 & 192 & 176 & 16 & 91.67 & 93.75 & -2.08 \\
\hline BC3F1-5-26 & 192 & 176 & 16 & 91.67 & 93.75 & -2.08 \\
\hline BC3F1-5-27 & 192 & 178 & 14 & 92.71 & 93.75 & -1.04 \\
\hline BC3F1-5-28 & 192 & 176 & 16 & 91.67 & 93.75 & -2.08 \\
\hline BC3F1-5-29 & 192 & 176 & 16 & 91.67 & 93.75 & -2.08 \\
\hline BC3F1-5-30 & 192 & 182 & 10 & 94.79 & 93.75 & 1.04 \\
\hline BC3F1-5-31 & 192 & 178 & 14 & 92.71 & 93.75 & -1.04 \\
\hline BC3F1-5-32 & 192 & 180 & 12 & 93.75 & 93.75 & 0.00 \\
\hline BC3F1-5-33 & 192 & 176 & 16 & 91.67 & 93.75 & -2.08 \\
\hline BC3F1-5-34 & 192 & 178 & 14 & 92.71 & 93.75 & -1.04 \\
\hline BC3F1-5-35 & 192 & 176 & 16 & 91.67 & 93.75 & -2.08 \\
\hline BC3F1-5-36 & 192 & 178 & 14 & 92.71 & 93.75 & -1.04 \\
\hline BC3F1-5-37 & 192 & 172 & 20 & 89.58 & 93.75 & -4.17 \\
\hline BC3F1-5-38 & 192 & 180 & 12 & 93.75 & 93.75 & 0.00 \\
\hline BC3F1-5-39 & 192 & 176 & 16 & 91.67 & 93.75 & -2.08 \\
\hline BC3F1-5-40 & 192 & 168 & 24 & 87.50 & 93.75 & -6.25 \\
\hline BC3F1-5-41 & 192 & 178 & 14 & 92.71 & 93.75 & -1.04 \\
\hline BC3F1-5-42 & 192 & 184 & 08 & 95.83 & 93.75 & 2.08 \\
\hline BC3F1-5-43 & 192 & 180 & 12 & 93.75 & 93.75 & 0.00 \\
\hline BC3F1-5-44 & 192 & 176 & 16 & 91.67 & 93.75 & -2.08 \\
\hline \multirow[t]{4}{*}{ BC3F1-5-45 } & 192 & 176 & 16 & 91.67 & 93.75 & -2.08 \\
\hline & & & Average & 92.86 & 93.75 & \\
\hline & & & Min. & 87.50 & & \\
\hline & & & Max. & 96.88 & & \\
\hline
\end{tabular}

*Average recurrent parent genome recovery expected in traditional backcross method 
Table 3 : Comparison of parents and novel male sterile line 'MAS99A'for morphological traits

\begin{tabular}{|c|c|c|c|c|c|c|c|c|}
\hline Entry & Description & $\begin{array}{l}\text { No. of } \\
\text { plants }\end{array}$ & $\begin{array}{l}\text { Days to } 50 \% \\
\text { flowering }\end{array}$ & $\begin{array}{l}\text { Plant height } \\
\text { at maturity }(\mathrm{cm})\end{array}$ & $\begin{array}{l}\text { Total number } \\
\text { of tillers }\end{array}$ & $\begin{array}{l}\text { Days to } \\
\text { maturity }\end{array}$ & $\begin{array}{l}\text { Panicle } \\
\text { length }(\mathrm{cm})\end{array}$ & $\begin{array}{l}\text { Spikelet per } \\
\text { panicle }\end{array}$ \\
\hline KCMS31A & Donor parent & 10 & 106.60 & 66.17 & 25.80 & 138.80 & 17.45 & 126.87 \\
\hline MAS99B & Recipient parent & 10 & 95.17 & 74.50 & 22.80 & 126.60 & 19.04 & 128.83 \\
\hline MAS99A & $\begin{array}{l}\text { Developed in } \\
\text { this research }\end{array}$ & 10 & 96.07 & 72.73 & 21.73 & 130.67 & 18.41 & 127.12 \\
\hline $\begin{array}{l}\text { T test } \\
\text { between } 2 \& 3\end{array}$ & & 10 & n.s & n.s & n.s & * & n.s & n.s \\
\hline
\end{tabular}

n.s and ${ }^{*}$, indicate non-significance and significance at $5 \%$ level of probability respectively

was carried out for the selection of $\mathrm{BC}_{3} \mathrm{~F}_{1}$ individuals with maximum of 'MAS99' genome (Fig.4).

Adaption of MABS allowed us to recognise plants which recovered maximum of recurrent parent genome up to $96.88 \%$ in $\mathrm{BC}_{3} \mathrm{~F}_{1}$ itself which was $3.13 \%$ more than expected average recovery, thereby new male sterile lines could be developed in just four backcrosses. Similar results were reported by Chen et al. (2001); Joseph et al. (2004) and Gopalakrishnan et al. (2008).

Development of new male sterile lines is a pre-requisite to step up the hybridization programme under aerobic condition. As evidenced from 't-test' analysis, the trait means of 'MAS99A line' were statistically on par with original fertile counterpart MAS99 B line besides 100\% pollen and spikelet sterility (Table 3; Fig.5). Indicated that the genome of recurrent parent was completely recovered, except some negligible proportion in $\mathrm{BC}_{4}$ itself. As use of markers helped us to select and advance superior plants in $\mathrm{BC}_{3}$ unlike in conventional backcross breeding it will take $\mathrm{BC}_{6}$ or $\mathrm{BC}_{7}$ generation to recover. The results of the present study again confirmed the power of MAS in back crossing for the recovery of recurrent parent genome in limited generations. Similarly using MABB, Ahmadikhah et al. (2015) reported that $\mathrm{BC}_{4} \mathrm{~F}_{1}$ male sterile plants were comparable to the original maintainer fertile counterpart for agronomic traits. However, Luu et al. (2012) successfully introgressed SUB1 into AS996 rice variety in just four backcrosses with $100 \%$ genome recovery. Whereas, SUB1 was introgressed to swarna rice variety in just three back crosses with complete genome recovery (Neeraja et al., 2006). Similary, $\mathrm{Hu}$ et al. (2016) demonstrated that MABB is a very efficient approach to improve BPH resistance of elite rice cultivar of South China, 'Hemeizhan' in three backcrosses.

New rice male sterile line 'MAS99A' with short duration, suitable for aerobic condition was developed in just four back crosses in the present study with the application of MABB using SSR markers. It is expected that newly developed male sterile line will be useful in development of new heterotic and short duration rice hybrids suitable for aerobic condition. This would help in expansion of hybrid rice cultivation to those areas of world where water availability is less so that an augmented production and productivity of rice could be achieved.

\section{Acknowledgment}

Authors are extremely grateful to the MAS Lab, Department of Genetics and Plant Breeding, University of Agricultural Sciences (UAS), GKVK, Bengaluru, India for providing financial assistance and all necessary facilities to carry out this research work.

\section{References}

Ahmadikhah, A., M. Mehdi, H.P. Mohammad and N. Leila : Markerassisted backcrossing (MABC) using CMS-specific, SSR and ISSR markers to develop an elite CMS line in rice. The Plant Genome, 31, 1-78 (2015).

Bai, J.Y., X.P. Zhang,Y. Jia, Chuan and Bao : Comparison of different foreground and background selection methods in marker-assisted introgression. Acta Genet.Sin., 33, 1073-1080 (2006).

Berloo, V.R.: GGT 2.0: Versatile software for visualization and analysis of genetic data. J. Heredity, 99, 232-236 (2008).

Bouchez, A.F., M. Hospital, A.G. Causse and A. Charcosset : Markerassisted Introgression of favourable alleles at quantitative trait loci between maize elite lines. Genetics, 162, 1945-1959 (2002).

Cao, D. and J.H.Oard : Pedigree and RAPD based DNA analysis of commercial U.S. Rice cultivars. Crop Sci., 90, 835-838 (1997).

Chen, S., X.H.Lin, C.G. Xu and Q. Zhang : Improving bacterial blight resistance of '6078', an elite restorer line of hybrid rice, by molecular marker-aided selection. Plant Breed., 120,133-137 (2001).

Frisch, M. and A.E. Melchinger : Selection theory for marker-assisted backcrossing. Genetics, 170, 909-917(2005).

Gandhi, V. R., M. Shivamurthy, N. S. Rudresh and S. Hittalmani : Performance and adaption of new aerobic rice variety MAS946-1 (Sharada) in southern Karnataka. Karnataka J. Agric. Sci., 25,5-8 (2011).

Gopalakrishnan, S., R.K. Sharma, K.A. Rajkumar, M. Joseph, V.P. Singh, A.K.Singh, K.V. Bhat, N.K. Singh and T. Mohapatra : Integrating marker assisted background analysis with foreground selection for identification of superior bacterial blight resistant recombinants in Basmati rice. Plant Breed., 127, 131-139 (2008). 
Hien, T.V., D.L. Duc, M. Abdelbagi, Ismail and H.L. Ham : Marker-assisted backcrossing (MABC) for improved salinity tolerance in rice (Oryza sativa L.) to cope with climate change in Vietnam. Australian J. Crop Sci., 6, 1649-1654 (2012).

Hittalmani, S. and G. Shivashankar : Out crossing on male sterile lines of rice. Mysore J. Agri. Sci., 21, 158-160 (1987).

Hospital, F. and A.Charcosset : Marker assisted introgression of quantitative trait loci. Genetics, 147, 1469-1485(1997).

Hospital, F.: Challenges for effective marker-assisted selection in plants. Genetics, 136, 303-310 (2009).

Hospital, F.: Size of donor chromosome segments around introgressed loci and reduction of linkage Drag in marker-assisted backcross programmes. Genetics, 158, 1363-1379 (2001).

Hu, W., H. Xiao, K.Hu, Y. Jiang and Y. Zhang : Application of markerassisted backcross to introgress Bph3, Bph14 and Bph15 into an elite indica rice variety for improving its resistance to brown plant hopper. Plant Breed.,135, 291-300 (2016).

Jena, K.K. and D.J. Mackill : Molecular markers and their use in markerassisted selection in rice. Crop Sci., 48, 1266-1276 (2008).

Joseph, M., S. Gopalakrishnan, R.K. Sharma, A.K.Singh, V.P.Singh, N.K. Singh and T. Mohapatra : Combining bacterial blight resistance and basmati quality characteristics by phenotypic and molecular marker assisted selection in rice. Mol. Breed., 13, 377-387 (2004).

Katsuo, K. and V.Mizushima: Studies on the cytoplasmic differences among rice varieties Oryza sativa $L$. on the fertility of hybrids obtained reciprocally between cultivated and wild varieties. Japan. J. Breed., 8, 1-5 (1958).

Kumar, K.G. and S. Hittalmani : Marker assisted backcross gene introgression of major genes for blast resistance in rice- Advances in Rice Blast Research, Kluwer Publications, pp. 43-45 (2000).

Kumar,S., S. K.Dwivedi,S.S. Singh, K.Sanjeev, P.K. Sundaram, Shivani and A.K. Mall : Characterization of rice (Oryza sativa L.) genotypes on the basis of morpho-physiological and biochemical traits grown under aerobic situation in rainfed ecosystem. J. Environ. Biol., 36, 999-1005 (2015).

Liu, Q.Q., Q.F.Li, X.L.Cai, H.M.Wang, S.Z.Tang, H.X.Yu, Z.Y. Wang and M.H.Gu : Molecular marker-assisted selection for improved cooking and eating quality of two elite parents of hybrid rice. Crop Sci., 46, 2354-2360 (2006).

Luu, M.C., N.H.Luu, M.H.Pham, T.H. Vu, Q.D.Nguyen, T.M.Pham, D.Q.Vu, M.I. Abdelbagi and H.H.Le :Application of marker assisted backcrossing to introgress the submergence tolerance QTL SUB1 into the Vietnam Elite Rice Variety-AS996. American J. Plant Sci., 3, 528-536 (2012).

Manivannan, N., T. Anandan, R. Chandirakala, P.Vindhiyavarman, V.
Muralidharan and K. Ganesamurthy : New male sterile lines in sunflower. Electron. J. Plant Breed., 2, 58-61 (2011).

Maureen, R.H. and B. Stephane : Interactions of mitochondrial and nuclear genes that affect male gametophyte development. The Plant Cell., 16, S154-S169 (2004).

Naresh Babu, N., N. Shivakumarand and S. Hittalmani : Pollen fertility vs spikelet fertility in $\mathrm{F}_{2}$ of a CMS based hybrids in rice (Oryza sativa L.) under aerobic condition. Electron. J .Plant Breed.,1, 789-793 (2010).

Neeraja, C.N., R. Maghirang, A. Pamplona, S. Heuer, B.C. Collard, E.M. Septiningsih, G. Vergara, D. Sanchez, K. Xu, A.M. Ismail and D.J. Mackill : A marker-assisted backcross approach for developing submergence-tolerant rice cultivars. Theor. Appl. Genet., 115, 757776 (2006).

Pan, X.B., Z.X. Chen, S.M. Zuo, Y.F. Zhang, X.J. Wu, N. Ma, Q.X. Jiang, J.H. Que and C.H.Zhou: Anew rice cultivar Wulingjing 1 resistant to rice stripe virus developed by marker assisted selection. Acta Agron. Sin., 35, 1851-1857 (2009).

Raj, K.G. and S.S.Virmani : Allelismtest for restorer genes of six promising IR restorer lines. Rice Genet. Newslett., 3, 23-24 (1987).

Sampath, S. and H.K.Mohantu : Cytology of semi sterile rice hybrid. Curr. Sci., 23, 182-183 (1954).

Semgan, K.A., M.N. Bjornstad and Ndjiondjop : Progress and prospects of marker assisted backcrossing as a tool in crop breeding programmes. African J. Biotechnol., 5, 2588-2603 (2006).

Standard Evaluation System for Rice (SES). : Prepared by INGER Genetic Resources Center, International Rice Research Institute, Manila, Philippines, pp.1-39 (1996).

Tanksley, S.D., N.D.Young,A.H. Paterson and M.W. Bonierbale : RFLP mapping in plant breeding: New tools for an old science. Biotechnol.Tech., 7, 257-264 (1989).

Yao, F.Y., C.G.Xu, S.B.Yu, J.X.Li, Y.J.Gao, X.H. Li and Q.F. Zhang : Mapping and genetic analysis of two fertility restorer loci in the wildabortive cytoplasmic male sterility system of rice (Oryza sativa L.). Euphytica, 98, 183-187 (1997).

Yi, M., K.T.New, A. Vanavichit, W. Chai-arree and T. Toojinda : Marker assisted backcross breeding to improve cooking quality traits in Myanmar rice cultivar Manawthukha. Field Crops Res., 113, 178-186 (2009).

Young, N.D. and M. Tanksley : RFLP analysis of the size of chromosomal segments retained around the tm-2 locus of tomato during backcross breeding. Theor. Appl. Genet., 77, 353-359 (1989).

Zhang, T.X., C.C.Jan,J.F. Miller and G.N., Fick : Inheritance of fertility restoration for two cytoplasmic male sterility sources of Helianthus pauciflorus (rigidus) Nutt. Crop Sci., 42, 1873-1875 (2002). 